Florida International University FIU Digital Commons

3-13-2003

\title{
The effects of rote and note teaching on the performance of high school chorus
}

Radio Cremata

DOI: $10.25148 /$ etd.FI14061541

Follow this and additional works at: https://digitalcommons.fiu.edu/etd

Part of the Music Education Commons

\section{Recommended Citation}

Cremata, Radio, "The effects of rote and note teaching on the performance of high school chorus" (2003). FIU Electronic Theses and Dissertations. 2486.

https://digitalcommons.fiu.edu/etd/2486

This work is brought to you for free and open access by the University Graduate School at FIU Digital Commons. It has been accepted for inclusion in FIU Electronic Theses and Dissertations by an authorized administrator of FIU Digital Commons. For more information, please contact dcc@fiu.edu. 
FLORIDA INTERNATIONAL UNIVERSITY

Miami, Florida

THE EFFECTS OF ROTE AND NOTE TEACHING ON

THE PERFORMANCE OF HIGH SCHOOL CHORUS

A thesis submitted in partial fulfillment of the

requirements for the degree of

MASTER OF SCIENCE

in

MUSIC EDUCATION

by

Radio Cremata

2003 
To: Dean Arthur W. Herriott

College of Arts and Sciences

This thesis, written by Radio Cremata, and entitled The Effects of Rote and Note Teaching on the Performance of High School Chorus, having been approved in respect to style and intellectual content, is referred to you for judgment.

We have read this thesis and recommend that it be approved.

Dr. Dan Hardin

Dr. Joseph Rohm

Dr. Michael Wagner, Major Professor

Date of Defense: March 13, 2003

The thesis of Radio Cremata is approved

Florida International University, 2003 


\section{DEDICATION}

I dedicate this thesis to my family: my mother Claire for her constant support and unending love for my music; her parents Emile and Rose through whom I believe I was given the gift of music; my father Radio Jr. for his immeasurable love and his simple words of wisdom that always help me stay focused; his parents Radio Sr. and Araceli for not only their unconditional love, but also for giving up their homeland and bringing my father to the United States in search of freedom and prosperity; my sisters Michelle and Denise for setting a standard of excellence that I can always look toward to help me achieve my goals; to my father in-law Allan for his love of children and music and for inspiring me to follow my dreams; and lastly to my incredible wife Mary for her enchanting love, encouragement and tremendous ambition. Without my family, the completion of this work would not have been possible. 


\section{ACKNOWLEDGMENTS}

I would like to thank the faculty and staff of Florida International University for their guidance, support and professional contribution to this work. Dr. Hardin has been especially helpful in teaching me about research techniques. Thanks to him this report is thorough and complete. Dr. Rohm helped me gain a greater appreciation for teaching music. By observing his classes, I have learned many techniques of communicating complicated musical ideas in a simple fashion. Studying with Dr. John Augenblick has helped me gain a greater appreciation for achieving musical excellence from my own students, even when circumstances are not favorable. His impeccable attention to detail, organization and class discipline has inspired me to be a better educator. Many of the professors in the Education department have both challenged and spiked my curiosity concerning educational issues that I might otherwise have never considered. I thank them, and my students are reaping the benefits of their priceless ideas. Lastly, I would like to thank my major professor, Dr. Michael Wagner for helping me learn to love school again. When we first met I had very different ideas about what classrooms were really about. He has been much more than just a teacher; he has taught me to believe in education and as a result, my current and future students will forever have a taste of his educational legacy. 


\section{ABSTRACT OF THE THESIS \\ THE EFFECTS OF ROTE AND NOTE TEACHING ON \\ THE PERFORMANCE OF HIGH SCHOOL CHORUS}

by

\section{Radio Cremata}

Florida International University, 2003

Miami, Florida

Professor Michael Wagner, Major Professor

The purpose of this research is to compare the effects two different teaching techniquesrote and note--have upon high school chorus. Rote instruction involves teaching students who do not have music in front of them. Note instruction involves teaching students who do have music in front of them. The methodology counterbalanced two different high school choirs. Rote and note taught groups were taught four of the same 3-part SAB chorale settings type music. Two recordings were made of each song for each group once after 30 minutes of instruction and second 24 hours later to test retention. Recordings were randomized and mastered onto $\mathrm{CD}$ and given to experts for evaluation. Across the board results were that rote taught groups scored higher than note taught groups on intonation, note accuracy and rhythm. This research does not recommend doing away entirely with note instruction. Rather, this research gives credence to rote as a valid music learning technique, often misunderstood because of the conflicting reports found in the professional literature. 


\section{TABLE OF CONTENTS}

CHAPTER

PAGE

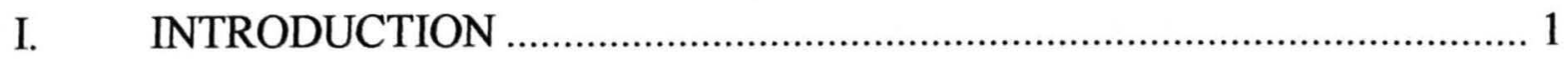

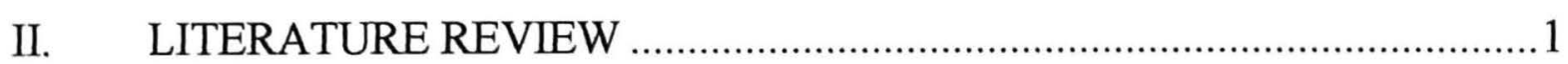

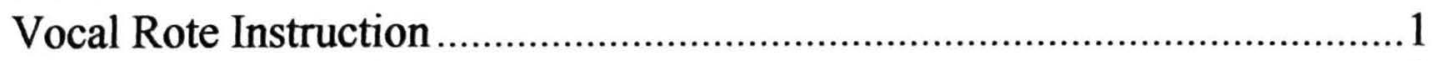

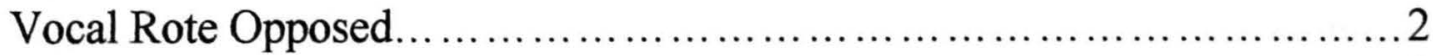

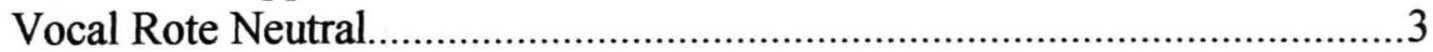

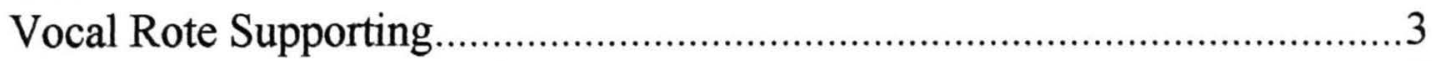

Instrumental Rote Instruction ..............................................................

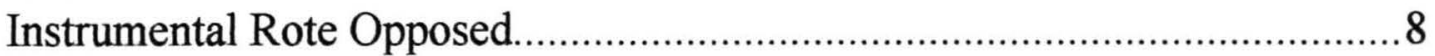

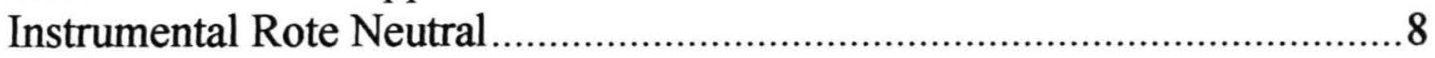

Instrumental Rote Supporting ................................................................

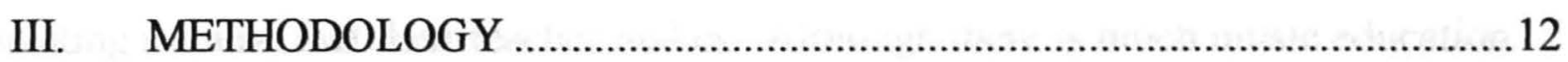

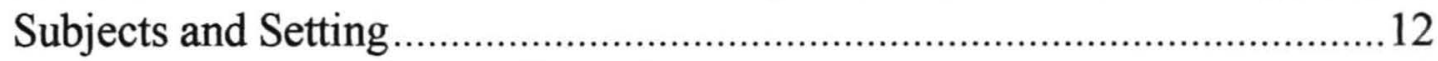

Data Collection Technique/Procedure ...........................................................12

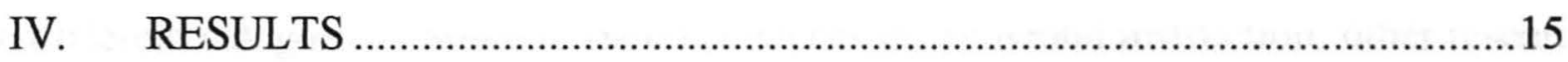

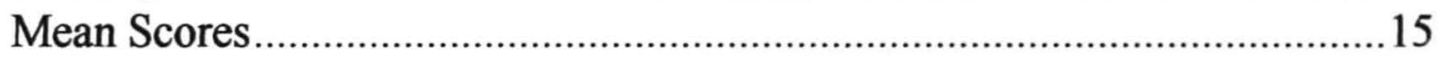

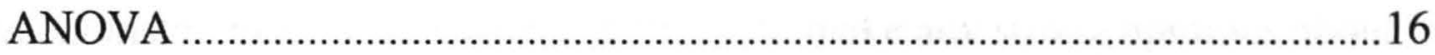

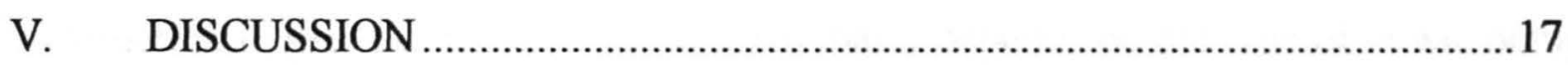

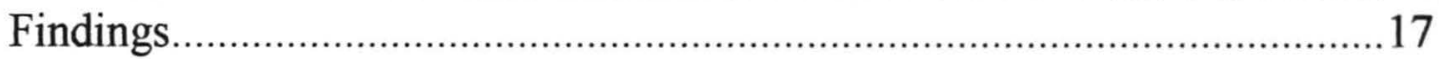

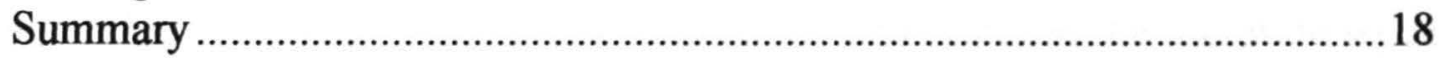

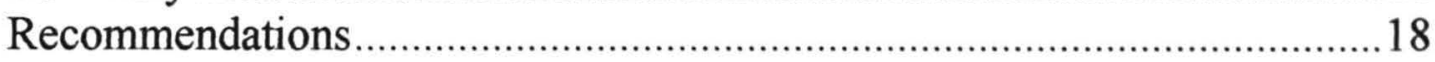

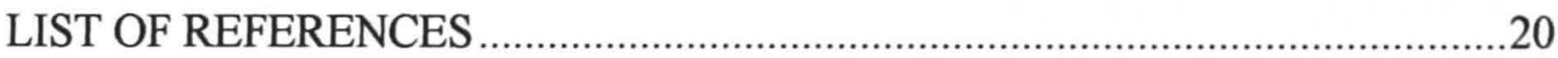

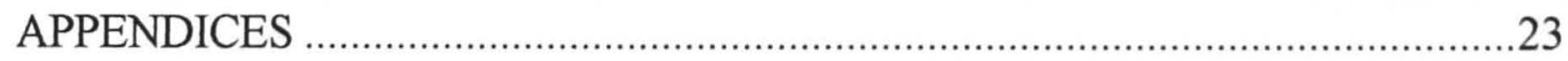


Every music educator has the option of using standard music notation or rote instruction as a basis for teaching or communicating a musical idea or composition to his or her students. Should music teachers teach by rote or by notation? Is either form of instruction preferable to the development of future musicians? Strict adherence to standard music notation instruction may emphasize teaching students how to read music so well that sight-reading a complicated score becomes a simple task. The alternative would be strict adherence to rote instruction where sight-reading is not the emphasis but rather where teacher-student echoing is emphasized. Rote instruction involves students emulating a sound that their teacher makes. Although there is much music education research concerning the issue of rote instruction, it appears that much of it is organized into different categories. Some research concerns instrumental instruction; other research examines vocal instruction. This makes it difficult to make any strong opinions about rote instruction in general, since it would seem that it depends on the type of music being taught - vocal or instrumental. This review will survey and organize the literature so that we can better understand the overall advantages and disadvantages of rote instruction in music education.

\section{Literature Review}

\section{Vocal Rote Instruction}

The bulk of the research concerning vocal rote instruction indicates that students learn best when teachers incorporate rote instruction techniques into their lesson. However, some studies indicate the contrary. This section begins with a discussion of the literature opposed to vocal rote instruction. Next, the discussion focuses on the literature 
with neutral findings neither opposing nor supporting vocal rote instruction. Finally, the discussion reviews the literature in favor of vocal rote instruction.

\section{Opposed:}

Rote instruction tends to hinder the student's learning process (Moore, et al, 1997). This research entitled, "Effects of Culture, Age, Gender and Repeated Trials on Rote Song Learning Skills of Children 6-9 Years Old from England, Panama, Poland, Spain, and the United States," concluded that students taught by rote often repeated their own mistakes rather than improving with repeated trials. The researchers concluded that rote instruction has an inherent problem, arguing that repeated mistakes without concrete notation to correct the error could lead a student to not learn his or her part well. Another problem noted was that, since students learned the music in parts, they could not perform the music seamlessly or entirely. Students did not understand the music as an entire piece, but rather as many parts of a whole.

Sunderland (1994) examined the sight-reading skills of selected Ohio secondary choral ensembles. The author found that all directors of the ensembles in the study used rote-teaching techniques to teach rhythms and pitches. However, the better sight-reading ensembles relied less on their directors and performed more varied repertoire. Better sight-readers tended to watch the notes more than the text and enjoyed singing next to singers in other sections of the ensemble. This research argues that students learning by standard notation tend to be better readers. Furthermore, students who were less rotereliant had more instrumental experience than their poor sight-reading counterparts.

Flowers (1990) reported rote vs. note instruction and isolated two elementary school singing groups. One group received direct standard notation instruction and 
further dissected the music into rhythmic and melodic parts. The other group received rote instruction without the dissected analysis. Results indicated that taught rhythmic and melodic patterns were performed with greater accuracy by the group that received direct standard notation instruction. In the researcher's pre- and post-test study, both groups improved their transfer of rhythmic and melodic patterns to music.

\section{Neutral:}

In research entitled: "The Effects of Systematic Rhythm Reading Instruction Versus Rote Rhythm Drill on the Pitch and Rhythm Sight-singing Performance of High School Choral Ensemble Members," no significant differences between rote or note instruction was found. (Egbert 1990) However, all students scored significantly higher on rhythm reading than on pitch reading. This finding was anticipated. According to the researcher, most high school students score higher on rhythm than pitch. Results also found that both groups experienced substantial gains in ensemble sight-reading. In a study involving several black gospel choirs in metropolitan New York, Allgood (1984) stated, the basic technique used in teaching a Black gospel tune is rote memory. (Allgood 1984) The study was used to evaluate issues of breath control, attacks, releases, vibrato, tone quality, and diction. However, conclusions showed no significant difference in quality.

\section{Supporting:}

The vast majority of the literature points to supporting vocal rote instruction as a viable technique in the classroom. This is a curious point since note instruction has been the standard form of music education for years in the western world. There appears to be 
a gap in the research where students of different levels and different age groups are compared to see which form of instruction suits them best.

Kane (1994) studied the difference between traditional rote instruction of music to kindergarten students and a different form of instruction called "tonal preparatory audiation guidance" which involves several stages of a child's musical development between ages 2-6. Results did not indicate that tonal preparatory audiation guidance was any more effective at teaching students than the traditional rote instruction. Kazez (1992) studied the effect of solfege drills on students trying to master melodies in sight-singing texts. The research indicated that preparation for a complicated piece of music for sightsinging was best done if students sang a "well-graded rote exercise" designed to correct the potential errors in pitch. This use of the rote technique was only used for exercises. Rote-style exercises develop pitch matching and ear training. (Kane1994) Shehan (1987) studied "Effect of Rote Versus Note Presentation of Rhythm Learning and Retention." The study was limited to second and sixth grade students; results indicated that by accessing both pathways to the brain, auditory and visual, better levels of learning and retention were achieved. Visual stimulus would include reading standard music notation while auditory stimulus would include rote instruction. This research favored the hybrid approach to instruction, taking the best parts of both techniques and using them to help nurture the student's development.

Waddell's (1989) research "Teaching a Rote Song" argues that rote song instruction is fundamental to the classroom. Songs taught by rote should be of a wide variety, including different tonalities, meters, styles and forms. (Waddell 1989) The researcher argues that rote songs should be taught with multiple repetitions involving 
tonal preparatory sequences or cues to help guide the singers. Additionally, accompaniments should be avoided because the rote song is best learned $a$ cappella. The argument continues that difficult phrases should be practiced on neutral syllables. Waddell does not say that standard notation instruction should be removed from the curriculum, but does say that rote technique has a place in the classroom. Jarjisian (1981) studied rote-singing achievement in young children, concluding that young students benefit more from both diatonic and pentatonic patterns of instruction through rote technique than by diatonic-only or pentatonic-only patterns of instruction. Further findings conclude that how well students rote sang was more influenced by instructional content and tonal aptitude than by teacher, school environments or socioeconomic status.

Some foreign cultures emphasize rote-based instruction over standard notation. It is also part of the tradition of much of the music in other cultures around the world that music is taught by rote. The passing down of songs and ideas by oral tradition is a foreign concept to westerners but is frequently practiced by other cultures. Research done by Malm (1972) dealt with the issue of teaching rhythmic concepts in ethnic music to students. Conclusions were that teaching rhythms in terms of bar lines is misleading. The researcher prefers rote instruction where students copy rhythmic patterns. The researcher goes on to argue that students learn better if they hear or perceive music not as an event-to-event sequence but rather as a time continuum. Trimillos (1983) analyzed the teaching/learning systems in music traditions around the world and found that rote instruction is an intercultural constant. One of Trimillos contentions is that by analyzing the way a culture transmits musical ideas to other members of the same culture, we can come to know how that culture thinks and we can hope to learn from their tradition. Rote 
instruction is found in ancient Hawaiian chants, in hula and in Indian classical music. Because learning has a vocal rather than instrumental basis, the voice is regarded as an important part of the learning process. It may be that standard notation is not an option for these foreign musicians, or it may be that the rote technique is favored. There did not appear to be any research comparing music instruction techniques in these cultures. The rote technique is the standard. Denny (1989) studied the music in liturgy and ritual of Islamic cultures and discovered that the oral aspect of rote learning is emphasized when teaching children, but that it is reinforced with training in writing. Denny noted that students of the Islamic culture learn by rote but also develop the written aspect of music through learning standard notation. This type of learning includes learning by rote and is then reinforced with practice writing out notation. This is not the same technique as students learning by rote while having the music in front them.

In terms of music instruction techniques in our western cultural heritage, Osterhout (1986) researched the history of note reading and regular singing in $18^{\text {th }}$ Century New England. Findings were that the traditional definition of "regular singing" has only included singing from written notation. However, his research indicates that singing by rote was a major part of the music of the $18^{\text {th }}$ century in New England.

Townsend (1996) studied "The Music Teaching and Learning Process in an African-American Baptist Church." (1996) Discoveries revealed that much of the learning choir members did was through oral transmission or rote. Choir members copied or sang the same thing that the director sang to them. First the director would sing the soprano part and then the sopranos would copy him. The director would sing all the parts to all sections, one by one and eventually all sections learned the music. This 
teaching technique, known as "lining out," normally occurs during rehearsal, though it can be incorporated into performances. Townsend argues that this teaching method would be appropriate in some classrooms if incorporated along with the African-American religious music since the two go hand in hand.

Bush (1985) delved deeper into rote music techniques in her research comparing two different ways of teaching a rote song - "Parrot" and "Reverse Chaining." Although the researcher admits the research does not come to any valid conclusions, the idea that rote instruction can be implemented by way of different techniques is an area for further investigation. Anderson (1995) examined the link between ear training and sight-reading skills in high school choral students. Much of the ear training significantly improved the students' sight-reading skills scores on the Arizona State Sight-Reading Testing Instrument.

Giles (1991) studied the use of Kodaly and Orff techniques to develop choral reading skills at the secondary level. These teaching techniques are a kind of rote instruction involving singing, ear training, solfege, rhythmic movement and improvisation. The researcher found that these techniques that are normally used with elementary level students may be extended through high school. This is positive evidence for rote instruction since some rote opponents might suggest that it is only good for young students.

\section{Instrumental Rote Instruction}

There is not as much literature published concerning instrumental rote instruction as there is on vocal rote instruction. However, the majority of the research in the instrumental area advances the idea that when teachers implement rote instruction 
techniques students benefit and in turn, learn quicker and better. First, the discussion will focus on the literature opposed to instrumental rote instruction and it will move towards the discussion of the literature taking a neutral stance on instrumental rote instruction, followed by discussion supporting instrumental rote instruction.

\section{Opposed:}

Lee (1992) studied the Suzuki principles of violin, finding that the method relied too heavily on rote teaching and that in turn students had less creativity and reading skills. Additionally, the repertoire was limited and poorly chosen, although this may not be attributable to the rote instruction. This study is not as comprehensive as Creider's (1989) research that will be discussed below in the "Supporting" section of the instrumental review. Shockley (1980) tackles the issue of piano music reading and memorization. The research here is built on the hypothesis that memory problems stem from rote methods of practice. A student will memorize a piece and then continue to play from memory. According to Shockley, this leads to a lesser understanding of the music being prepared and does not help develop other musical skills.

\section{Neutral:}

Lorenz (1993) studied the difference in instructional treatment for rote learning, improvisation and tonal conceptual development in a beginning guitar class. The researcher admits that results were not conclusive although it seemed that rote learning was just as effective as the other two instructional techniques. Grande (1989) compared the "rote-to-note" approach and the traditional music reading approach in teaching beginning instrumental music. The rote-to-note method that utilizes familiar rote songs and solfege singing was taught to one group and not to the other. Results did not yield 
sufficiently higher scores for either group to make significant conclusions on the merit of either instructional technique. Hahn (1985) investigated the correlations between reading music and reading language with implications for music instruction (notation). Students were divided into two groups. One group learned about notation in a "vacuum" while the other group learned about standard notation in the context of familiar musical patterns taught by rote. No significant conclusions were reached. The researcher proposed an alternate hypothesis that the rote instructional method was more effective than the traditional method currently being used to teach music reading and sight-reading.

\section{Supporting:}

Creider (1989) discusses music education using the Suzuki method. In Creider's view both hearing and rote learning are vehicles students can use to free themselves from the harmful and often counterproductive "music babble" that can confuse and discourage students from music reading. Suzuki instruction can be an effective method of music instruction if it is supplemented with a variety of musical experiences including concert and recordings, a balanced repertoire and lessons that build on one another through sequential activities. (Creider 1989) Glenn's (1999) research entitled "Rote vs. Note: The Relationship of Working Memory Capacity to Performance and Continuation in Beginning String Classes (sixth-grade, middle school)" concludes that significant differences exist between students who receive rote instruction and students who receive standard notation instruction. Performance scores were not different between the two groups; however, continuation was 40\% higher in the rote instructed group. Chen (1958) investigated students in kindergarten and their initial keyboard learning process. The research here indicated that the rote learning process allowed kindergarten students of 
any level of developmental music aptitude to learn to play a keyboard instrument within a short period of time.

Instrumental rote-based instruction may involve vocal techniques. Bloedel Beery (1996) investigated the effects of singing instruction on beginning instrumental students. Her findings concluded that using singing was an effective tool in developing musical expression for instrumental students. Students who sang their part before they played it mastered the music quicker and played with more expression.

When music gets more complicated, as in jazz improvisation, one might think that rote-based instruction has no place; however, Bash (1983) examined the connection between jazz improvisation skills and rote instruction. Three methods of instruction were compared. Among the three was an aural perceptive treatment that supplemented the scalar and chordal activities that students already received. The aural perceptive treatment involved vocal responses to blues patterns, vocalization of blues improvisation and instrumental echo response patterns using rote. Results suggested that this method of instruction could be encouraged for use in general music curriculum since students learned the improvisation technique rapidly and well.

A last bit of research here examines neither instrumental nor vocal music students. Stockton (1982) analyzed aural meter discrimination among college students in introductory music classes. Findings were that students who were taught by rote several rhythm patterns in multiple meters showed significantly higher gains in aural meter discrimination than did the control group that did not receive the rote instruction. Students who are taught to perform and identify rhythm patterns in various meters will achieve a higher level of rhythmic understanding than students who are taught to read, to 
listen to, and to identify various types of meter presented in recorded musical excerpts. (Stockton 1982)

Of the 31 studies in this review of literature 21 supported rote instruction while only 5 opposed it. The remaining 5 studies reported neutral results.

\section{Statement of the Problem}

The majority of the research supports rote instruction, yet there exists a popular belief among educators, especially at the secondary level and up, that rote instruction is silly, non-academic or counterproductive to the student's learning process. Educators and directors not supporting rote instruction may argue that although rote instruction may be effective at teaching songs it is ineffective at making students better prepared for future musical challenges. They may contend that serious music demands students who can read music. Non-rote supporters may go on to say that a well-developed ear is helpful and often necessary, but excellent reading skills are as important if not more so. Supporters of rote, on the contrary, may argue that rote instruction helps teachers teach their ensembles music they otherwise would not be able to perform if the ensembles were to rely exclusively on note instruction. Supporters may use rote merely as reinforcement for note instruction. All that said, educators and scholars seem to differ on their opinions about the worthiness of rote instruction in the classroom. Curiously, the majority of the research supporting rote instruction favors rote instruction for younger children. Therefore, this study aimed to investigate if rote instruction is effective for music students at the secondary level. By comparing rote and note instruction against one another, this study highlights the relative strengths and weaknesses of each type of 
instruction. The hypothesis of this research is that rote instruction will be more effective than note instruction for high school chorus in a choir's overall note accuracy, intonation and rhythm.

\section{Methodology}

\section{Subjects}

Two high school choirs from a private school in Southeastern Florida, of equal ability and experience, each comprised of 24 singers ages 14-19 participated in the study. Although students and parents were informed and signed consent/assent documents, none of the students knew when experiment began. They participated in their music class and all materials were related to their curriculum. The students in both groups did not know of the other's participation.

\section{Procedure}

Each group of students met with the same music teacher at a different time of day, but for the same amount of time. Each group of students, Choir A and Choir B, received both Rote and Note instruction. A counterbalanced design was employed.

Rote instruction was defined as having the students learn the song without having a copy of the music in front of them. The teacher would sing short phrases of the music to each section of the choir (call) and the students would sing back (response) to the teacher. The students never saw a copy of the music. As each section learned their individual parts, other sections would learn how the harmony fit by singing along with the other sections. (Refer to Appendix 1 for musical examples.) The teacher maintained a steady beat by snapping his fingers to the quarter note as the sections learned their music. The 
teacher never allowed interruptions nor did he allow questions. The steady beat of the finger-snap was maintained throughout the instructional time. When the singers sang incorrectly, the teacher would sing correctly and the students would respond in the traditional call and response fashion.

Note instruction was defined as giving students a clear copy of the music in SAB form. The teacher distributed the music and the students sat silently until the teacher called upon them to sight-read their parts. When students sang incorrectly the teacher would interrupt the students and ask for a volunteer to correctly sing the line. When intervals were incorrectly sung, students would be asked to stop and count the interval using numbers or solfege. If rhythms were incorrectly sung, students were asked to sing the numbers to the beats in time out loud. If an individual section of the choir was having trouble the teacher would work individually with that section. The teacher never sang the music to the students. The learning was done exclusively through sight-reading. The teacher only stopped them when mistakes were made, and mistakes were never corrected using rote instruction.

It should be mentioned that, to some degree at least, there is no such thing as pure note instruction. Some singers in a section may be stronger singers and therefore sing louder with more confidence and as a result teach other singers in their section the music by rote. Moreover, the repetition of singing in a rehearsal is in many ways a "rote-type" learning method. However, the idea that copies of the music were in front of each singer and that the teacher never sang nor played the music, certainly differentiates note from rote techniques. 
A total of four songs were used (Appendix 1). The music selected for the study was in chorale settings arranged in 3-part ( $\mathrm{SAB}$ ) functional and diatonic harmony. There were no key changes and all the music was in major keys. Selections were no longer than 32 measures and no shorter than 16 measures in length. The songs were not longer than 1 minute in length. In order to avoid the problem of learning words, each note was sung on the syllable "Ta." Each group of students was given the same 4 songs and 30 minutes of instructional time on each song. Choir A and B were, in counterbalanced fashion, given both rote and note instruction. The order and sequence of instruction is illustrated below (figure 1.a). Immediately after the 30 minutes expired, students were recorded onto a digital hard disk recorder. The recording was saved and 24 hours later, the students were again asked to sing the song without rehearsal. The results were also recorded onto the digital hard disk recorder.

Figure 1.a:

\begin{tabular}{|l|l|l|l|l|}
\hline & Day 1 Song 1 & Day 2 Song 2 & Day 3 Song 3 & Day 4 Song 4 \\
\hline Choir A & Rote & Note & Rote & Note \\
& 30 min instruction; record, & 30 min instruction; record, & 30 min instruction; record, & 30 min instruction; record, \\
& 24 hrs later record & 24 hrs later record & 24 hrs later record & 24 hrs later record \\
\hline Choir B & Note & Rote & Note & Rote \\
& 30 min instruction; record, & 30 min instruction; record, & 30 min instruction; record, & $\begin{array}{l}30 \text { min instruction; record, } \\
24 \text { hrs later record }\end{array}$ \\
& 24 hrs later record & 24 hrs later record & 24 hrs later record & \\
\hline
\end{tabular}

After all the recordings were made and the order randomized, the music was mastered onto $\mathrm{CD}$ (Appendix 2) and given to a panel of over sixty different musicians and music teachers for review. The experts consisted of four college professors, twenty- 
two school music teachers, twenty-three graduate students in music school and eighteen professional musicians. The panel of experts was also given a copy of the music and an adjudication form that contained three questions with a Likert scale answer (Appendix 3). The questions were the same for each of the 16 recordings ( 4 songs sung twice by two groups). Judges rated each performance for its intonation, note accuracy and rhythm. The data were collected and the results calculated.

\section{Results}

Mean scores for each of the three categories were calculated by first separating the songs taught by rote from those taught by note. Next the scores from the four different songs were compiled. Twelve mean scores (six for Rote, six for Note) were calculated. Figure 1.b below illustrates the mean scores.

Figure 1.b:

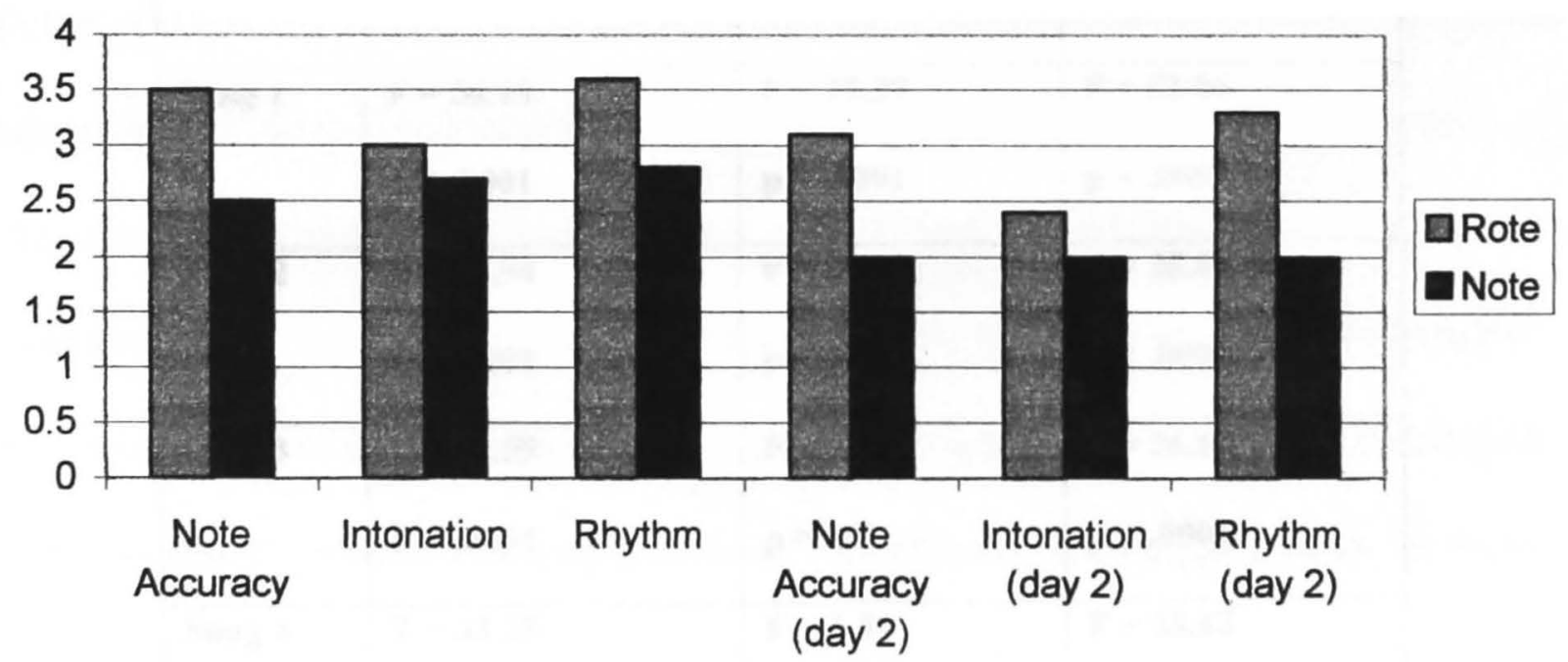


By comparing mean scores it was found that in every case, judges rated rote instruction (3.15) higher than they rated note instruction (2.33). Retention scores on day 2 were also dramatically greater on rote instruction (2.93) than on note instruction (2.00). Although rote scored higher than note in all three categories, the gap between the two was most dramatic over-all in the Note Accuracy category (Rote 3.30), (Note 2.25). The Intonation category had the smallest gap (Rote 2.70), (Note 2.35).

A series of ANOVAs were run on each variable for all songs to determine if scores on rote songs were significantly different than note songs. Figure 1.c below shows the computed $\mathrm{F}$ value for each variable and the probability that the score could have been obtained by chance alone. These $\mathrm{F}$ values were also compared to table values of $\mathrm{F}$ distributions. Any computed $\mathrm{F}$ value higher than the table value indicates significance above the chance level (Hicks 1964).

Figure 1.c:

\begin{tabular}{|c|c|c|c|}
\hline & Note Accuracy & Intonation & Rhythm \\
\hline Song 1 & $\begin{array}{l}F=56.19 \\
p<.0001\end{array}$ & $\begin{array}{l}F=29.29 \\
p<.0001\end{array}$ & $\begin{array}{l}F=52.86 \\
p<.0001\end{array}$ \\
\hline Song 2 & $\begin{array}{l}F=66.94 \\
P<.0001\end{array}$ & $\begin{array}{l}F=28.09 \\
p<.0001\end{array}$ & $\begin{array}{l}F=38.84 \\
p<.0001\end{array}$ \\
\hline Song 3 & $\begin{array}{l}F=19.59 \\
P<.0001\end{array}$ & $\begin{array}{l}F=1.94 \\
p=.17\end{array}$ & $\begin{array}{l}F=26.68 \\
p<.0001\end{array}$ \\
\hline Song 4 & $\begin{array}{l}F=33.25 \\
P<.0001\end{array}$ & $\begin{array}{l}F=5.89 \\
p=.016\end{array}$ & $\begin{array}{l}F=28.63 \\
p<.0001\end{array}$ \\
\hline
\end{tabular}


As can be seen, all variables using rote methodology are significantly higher than the scores for note, with the possible exception of intonation in song 3 where the probability of the obtained score being by chance is noticeably higher.

\section{Discussion}

This study provides some current data in the complicated, yet unresolved area of vocal rote instruction in music education research. These data indicate that groups taught by rote out-perform those taught by note in intonation, note accuracy, rhythm and retention of each of the previously mentioned categories. Although the findings were supportive of rote over note instruction, it is not advised dispensing entirely with note instruction. It is possible that the style of music used in this study may have been better suited for rote instruction than other kinds of music. Furthermore, a music education would not be complete without learning how to read. Ideally both types of instruction can be used in high school music education. However, as can be seen by these results, rote instruction is extremely important in preparing for performance. It would seem that students benefit from being taught via rote. Not only is it more effective than note instruction at bringing out the best in a high school choir's overall note accuracy, intonation and rhythm, but the choir's overall retention of the music is also maximized. Past research in music education has scrutinized both rote and note teaching techniques and the students' response to being stimulated on different learning pathways. If music teachers can access both the visual and aural senses of their students, using these techniques in combination will perhaps result in better and more accurate student performances. 
It is also worth noting that many musicians who suffer from blindness are most often limited to learning music via the rote method. Therefore in some cases, rote instruction is more than just an alternative to note instruction. The rights and needs of the handicapped must be addressed in schools. It would be interesting to see some research on handicapped students and their level of musical proficiency. Perhaps learning via rote is better at developing other, more sophisticated music skills.

Learning music via rote can be useful in situations where time is important. This study set up circumstances where the song was learned and recorded all in 30 minutes. It is handy in that regard because there is no intermediate step in the learning. There is no symbol that needs defining and explaining. Rote instruction takes advantage of this issue and bypasses that level of confusion. Therefore less time is spent translating and more time is spent making music. Although intonation seemed to have less of a significant difference between rote and note, intonation was still better in the rote songs. It may be that by concentrating wholly on the music and not the paper, singers of equal level and ability sing more in tune. As mentioned previously, this research does not recommend doing away entirely with note instruction. Rather, this research gives support to rote as a valid music-learning technique, often misunderstood because of the conflicting reports found in the professional literature.

In general, it appears that rote instruction serves an important role in music education. Results remain inconclusive; however, this study adds credence to the hypothesis that rote learning can be beneficial, especially in conjunction with note teaching. Rote instruction can -- and probably should -- be incorporated into note instruction. It would seem, because of the findings reported here, that teachers can tell 
their students to stop reading and listen. Experienced note teachers may find the strategy of fusing rote into the note lesson more feasible than pure rote. Either way, rote instruction is certainly something worth incorporating into a lesson. It is not just for musicians who cannot read. 


\section{References}

Allgood, B. D. "A Study of Selected Black Gospel Choirs in the Metropolitan New York Area." Ph.D diss., New York University, 1984.

Anderson, Dean Philip. "Integrating Instructional Ear-Training Techniques into a High School Choral Music Performance Class Curriculum to Improve Students' Sight-Reading Skills." Ph.D diss., Nova Southeastern University, 1995.

Baxh, Lee. "The Effectiveness of Three Instructional Methods on the Acquisition of Jazz Improvisation Skills." Ph.D diss., State University of New York at Buffalo, 1983.

Bloedel Beery, Catherine D. "The Effects of Structured Singing Instruction on Beginning Instrumental Students Performance Achievement." Master's Thesis, Michigan State University, 1996.

Bush, Margaret Ann. "A Comparison of the Two Procedures for Teaching a Rote Song: Parrot and Reverse Chaining (Imitation)." Ph.D diss., University of Missouri- Kansas, 1985.

Chen, Cheng-Ying. “An Investigation of Kindergarten Children's Initial Keyboard Learning Process and the Relationship of that Process to Developmental Music Aptitudes, Singing Performance, and Type of Instruction." Ph.D diss., Temple University, 1998.

Chivington, Amy D. "The Effect of Differential Choral Group Instruction on Children's Vocal and Rhythmic Performance of Taught and Transfer Patterns (Vocal Performance)." Ph.D diss., The Ohio State University, 1990.

Creider, Barbara Hanna. "Music Learning Theory and the Suzuki Method." Readings in Music Learning Theory (1989): 260-271.

Daniels, Rose Dwiggins. "Relationships Among Selected Factors and the SightReading Ability of High School Mixed Choirs." Journal of Research in Music Education 34, no. 4 (1986): 279-289.

Denny, Frederick Mathewson. "Qur'an recitation: A Tradition of Oral Performance and Transmission." Oral Tradition 4, no. 1-2 (Jan.-May 1989): $5-26$.

Egbert, Johnson Blythe. "The Effects of Systematic Rhythm Reading Instruction Versus Rote Rhythm Drill on the Pitch and Rhythm Sight-Singing Performance of High School Choral Ensemble Members." Ph.D diss., University of Missouri Columbia, 1990. 
Giles, Martha Mead. "Choral Reading Built on the Basics." Music Educators Journal 77 (1991): 26-29.

Glenn, Karen A. "Rote vs. Note: The Relationship of Working Memory Capacity to Performance and Continuation in Beginning String Classes (SixthGrade, Middle School." Ph.D diss., University of Northern Colorado, 1999.

Grande, Leon Edward. "A Comparison of the "Rote-To-Note" Approach and the Traditional Music Reading Approach in Teaching Beginning Instrumental Music," Ph.D diss., University of Lowell, 1989.

Hahn, Lois Blackburn. "Correlations Between Reading Music and Reading Language, with Implications for Music Instruction (notation)." Ph.D diss., The University of Arizona, 1985.

Hicks, Charles R. Fundamental Concepts in the Design of Experiments. New York: Holt, Reinhart and Winston, 1964.

Jarjisian, Catherine Strese. "The Effects of Pentatonic and/or Diatonic Pitch Pattern Instruction on the Rote-Singing Achievement of Young Children." Ph.D diss., Temple University, 1981.

Kane, Maryanne J. "The Effects of Teacher Training upon the Developmental Musical Aptitude and Music Achievement of Kindergarten Students." Ph.D diss., Temple University, 1994.

Kazez, Daniel I. "Solfege Drills." Jounal of Music Theory Pedagogy 6 (1992): 19-34.

Lee, Shirley Yon. "The Suzuki Beginner: A Teacher's Guide to the Suzuki Principles of Violin." DMA diss., University of Washington, 1992.

Lorenz, Kevin Wayne. "A Comparison of the Effectiveness of Three Teaching Methods Based on Rote Learning, Improvisation, and Tonal Conceptual Development on Melodic Performance Skills Achievement of Music Teachers in a Beginning Guitar Class." Ph.D diss., University of North Carolina at Greensboro, 1993.

Malm, William P. Teaching Rhythmic Concepts in Ethnic Music. Music Educators Journal 59, no. 2 (October 1972): 95-99. 
Moore, Randall Spencer, Melissa Brotons, Janina Fyk, and Argelis Castillo. "Effects of Culture, Age, Gender and Repeated Trials on Rote Song Learning Skills of Children 6-9 Years Old from England, Panama, Poland, Spain, and the United States." Bulletin of the Council for Research in Music Education 133 (Summer 1997): 83-88.

Osterhout, Paul. Note Reading and Regular Singing in Eighteenth-Century New England. American Music, 4, no. 2 (Summer 1986): 125-44.

Shehan, Patricia. "Effect of Rote Versus Note Presentation of Rhythm Learning and Retention." Journal of Research in Music Education 35 , no. 2 (Summer 1987): 117-26.

Shockley, Rebecca Payne. "An Experimental Approach to the Memorization of Piano Music with Implications for Music Reading" Ph.D diss., University of Colorado at Boulder, 1980.

Stockton, James Larry. "An Experimental Study of Two Approaches to the Development of Aural Meter Discrimination Among Students in a College Introductory Music Class." Ph.D diss., Temple University, 1982.

Sunderland, Martin R. "A Description of Selected Ohio Secondary Choral Ensembles with Particular Attention to Sight-Reading Skills." Ph.D diss., Univesity of Cincinnati, 1994.

Townsend, Robert Toussaint. "The Music Teaching and Learning Process in an African-American Baptist Church" $\mathrm{Ph} . \mathrm{D}$ diss., University of Illinois, UrbanaChampaign, 1996.

Turpin, Douglas. "Kodaly, Dalcroze, Orff, and Suzuki: Application in the Secondary Schools." Music Educators Journal 72 (February 1986): 56-59.

Trimillos, Ricardo. "The Formalized Transmission of Culture: Selectivity in Traditions Teaching/Learning Systems in Four High Skill Music Traditions." East-West Culture Learning Institute Report 9, no. 1-2 (May 1983): 1-9.

Waddell, Gail. "Teaching a Rote Song." Readings in Music Learning Theory (1989): G.I.A.: 84-91. 


\section{Appendix 1}

\section{"Sample" Adjudication Form}

You will be listening to 16 short recordings of different yet equally balanced and experienced choirs singing 4 songs. The music has been prepared by different teaching strategies. As a result some of the music will sound better than others. Please circle a number next to each category that best represents your impression of each recording in that category.

$\# 1$

$\begin{array}{lllll} & \text { 1= Poor } & \text { 2=Fair } & \text { 3=Good } & 4=\text { Excellent } \\ \text { 1. Note Accuracy } & 1 & 2 & 3 & 4 \\ \text { 2. Intonation } & 1 & 2 & 3 & 4 \\ \text { 3. Rhythm } & 1 & 2 & 3 & 4\end{array}$

$\# 2$

$$
\text { 1= Poor } \quad 2=\text { Fair } \quad 3=\text { Good } \quad 4=\text { Excellent }
$$

1. Note Accuracy $\quad 1 \quad 3 \quad 2 \quad 3 \quad 4$

$\begin{array}{lllll}\text { 2. Intonation } & 1 & 2 & 3 & 4\end{array}$

$\begin{array}{lllll}\text { 3. Rhythm } & 1 & 2 & 3 & 4\end{array}$

\#3

$$
\text { 1= Poor } \quad 2=\text { Fair } \quad 3=\text { Good } \quad 4=\text { Excellent }
$$

$\begin{array}{lllll}\text { 1. Note Accuracy } & 1 & 2 & 3 & 4 \\ \text { 2. Intonation } & 1 & 2 & 3 & 4\end{array}$

$\begin{array}{lllll}\text { 3. Rhythm } & 1 & 2 & 3 & 4\end{array}$




\section{Appendix 3}

Number 1

Robert Williams
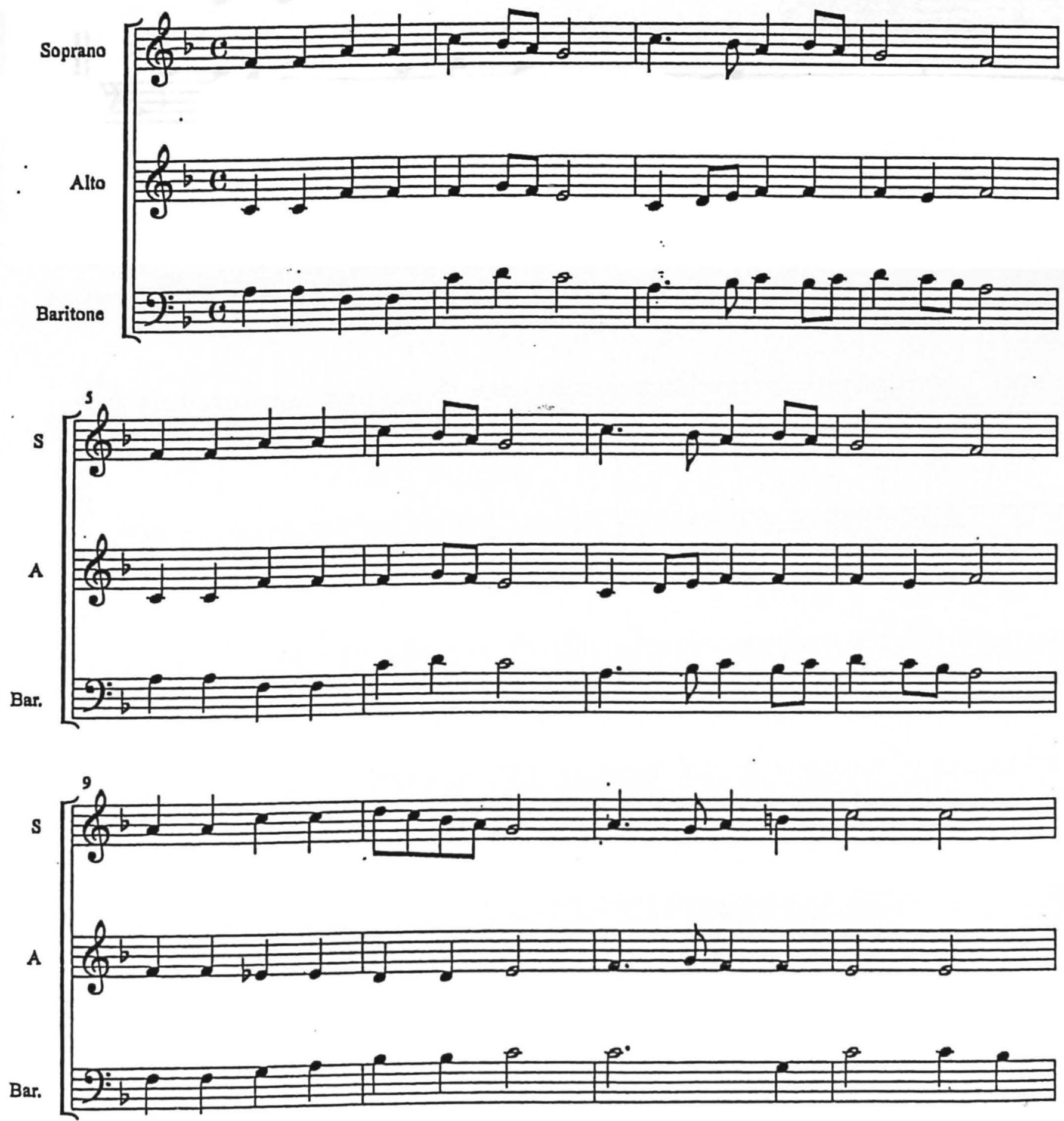

from: Llanfair (Hail the Day that Sees Him Rise) 


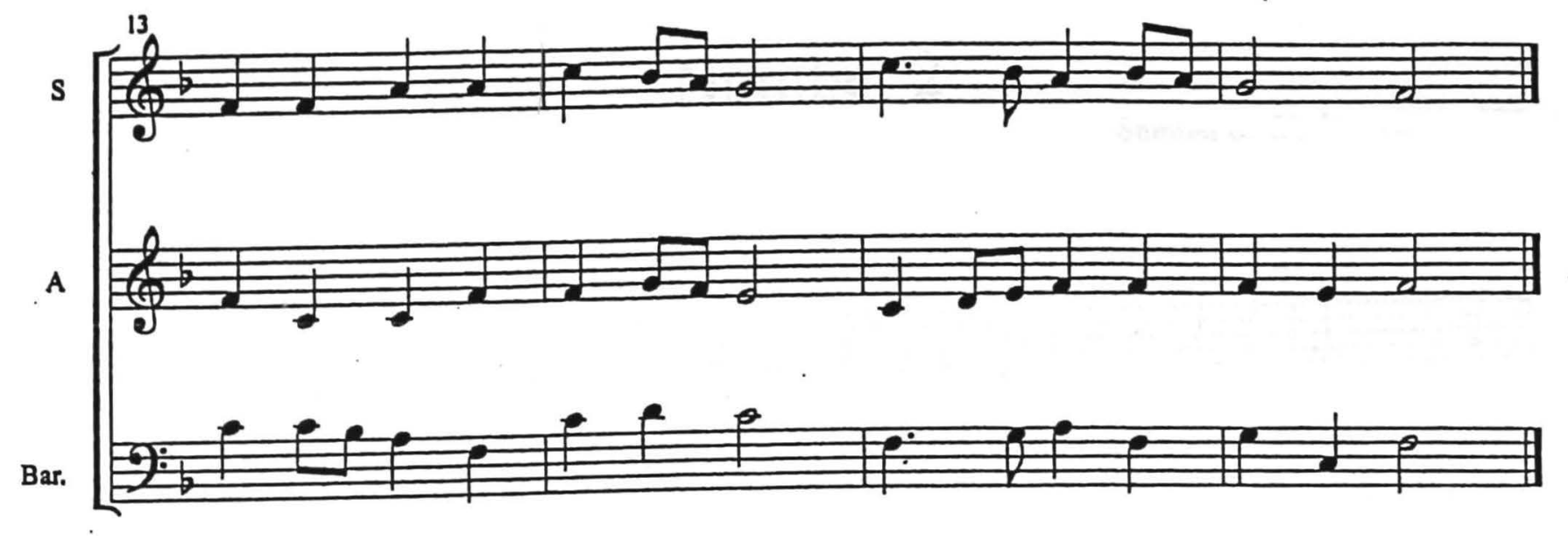


Number 2

Samuel S. Wesley, 1810-1876
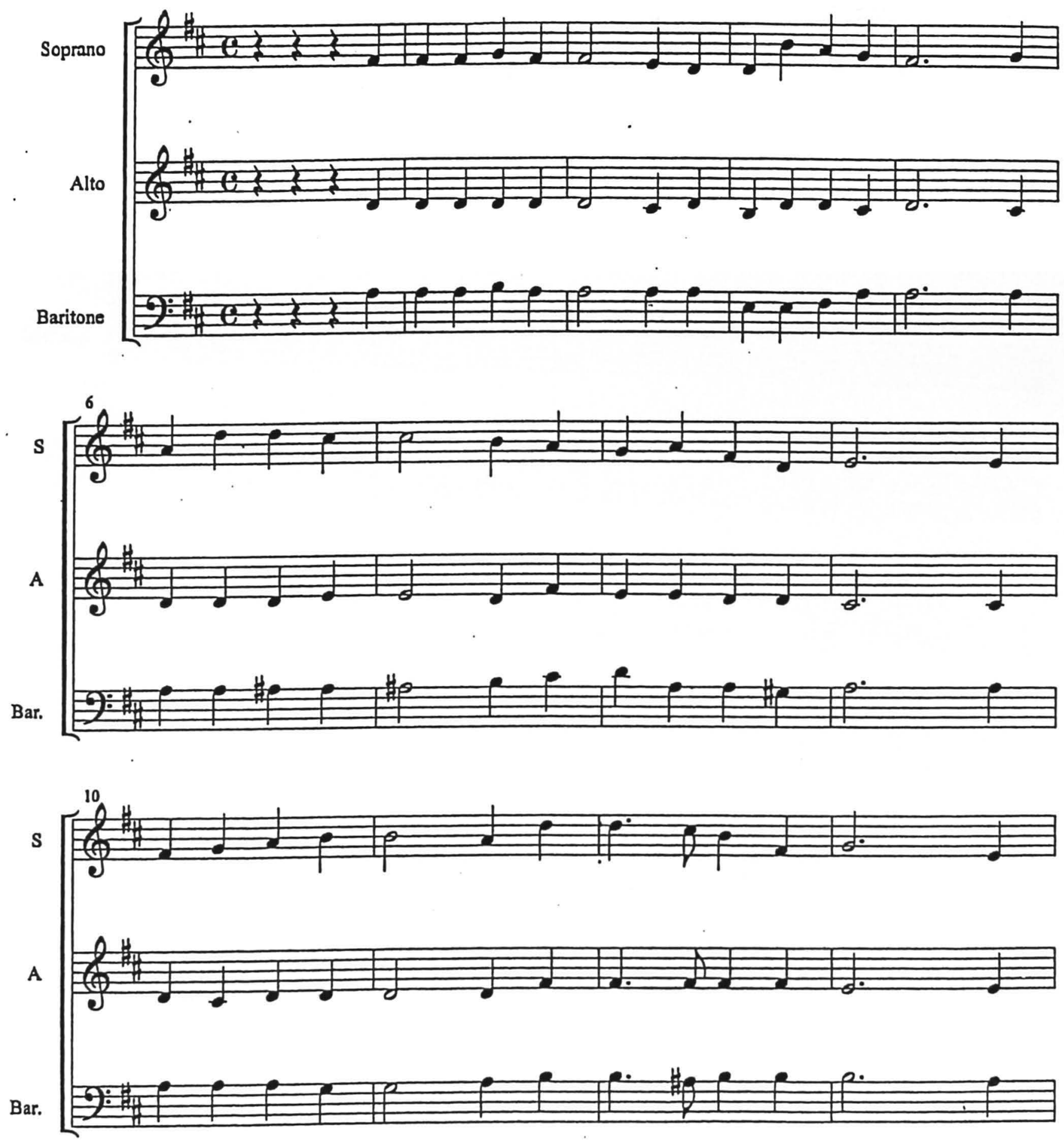

from, Aurelia 


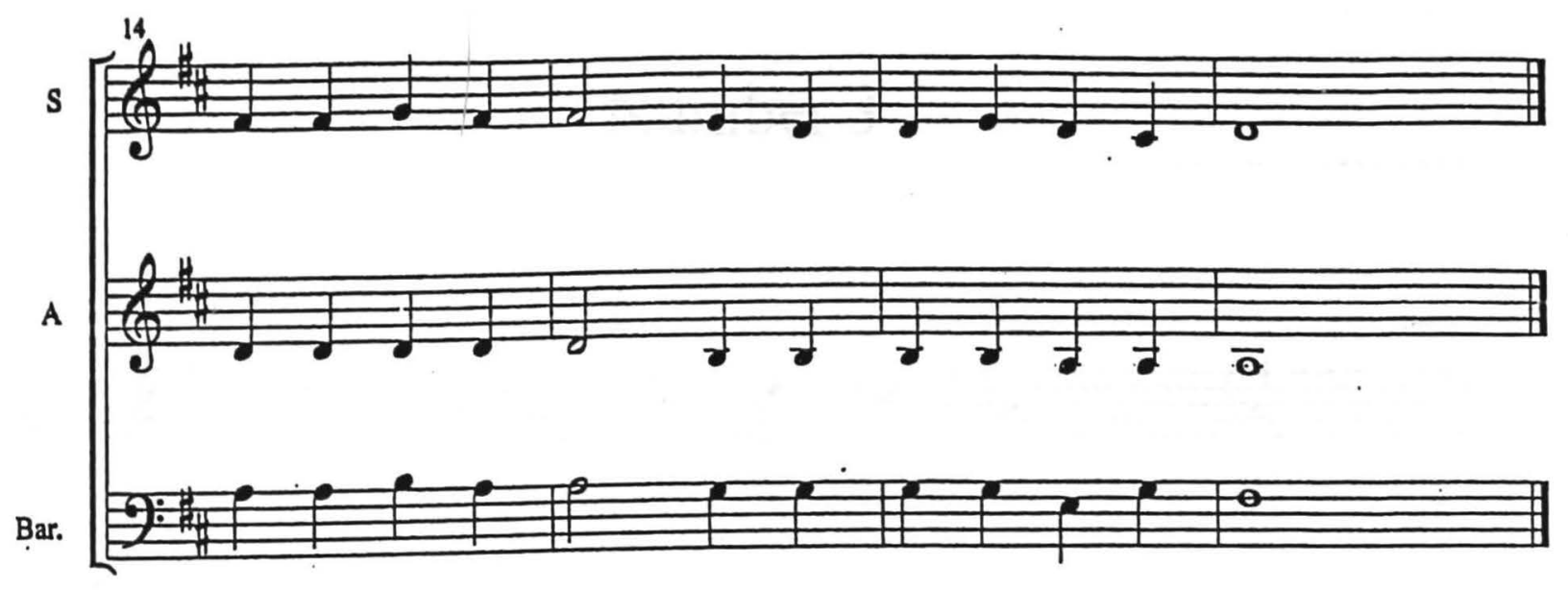




\section{Number 3}

John Goss 1800-1880
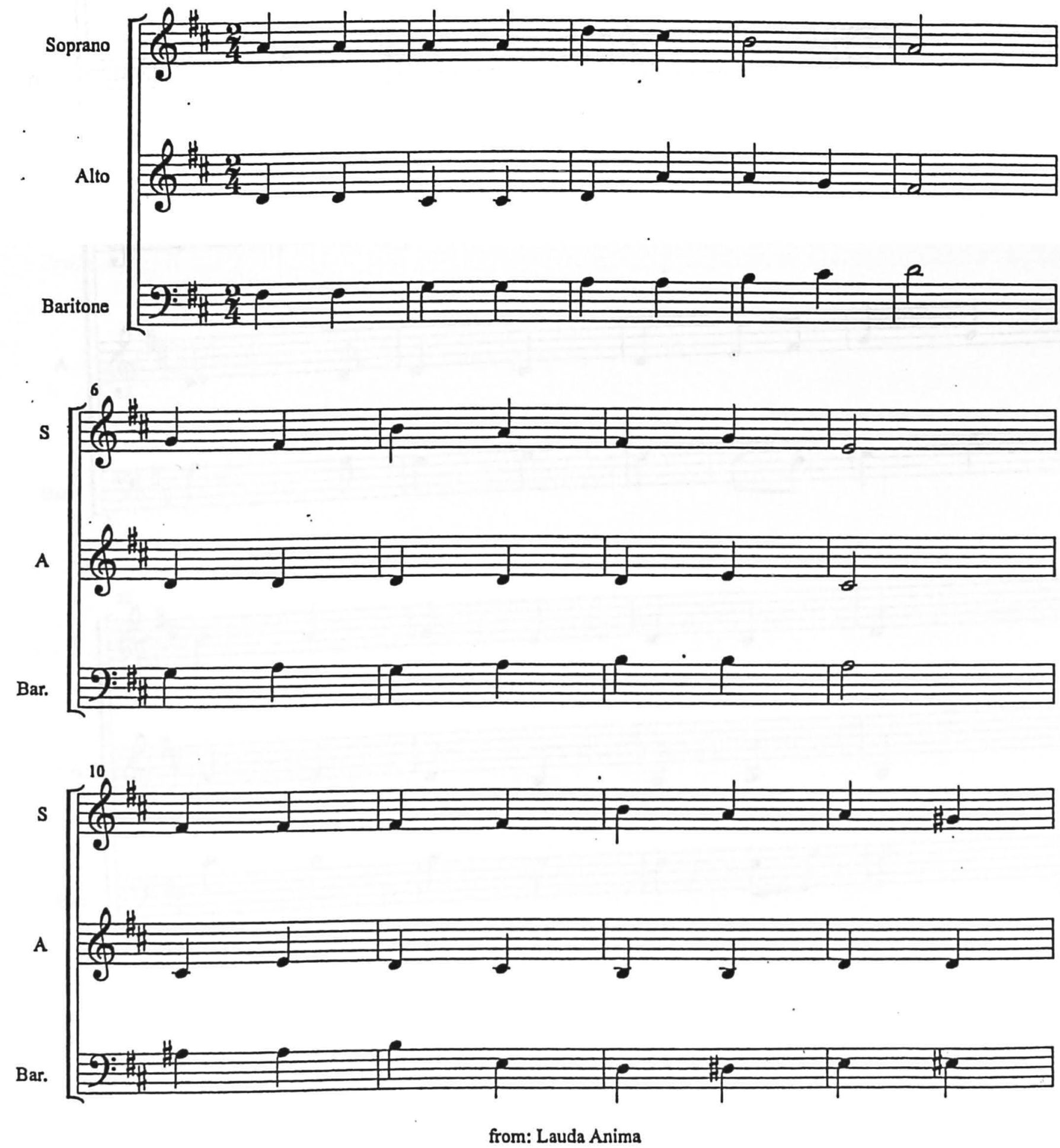

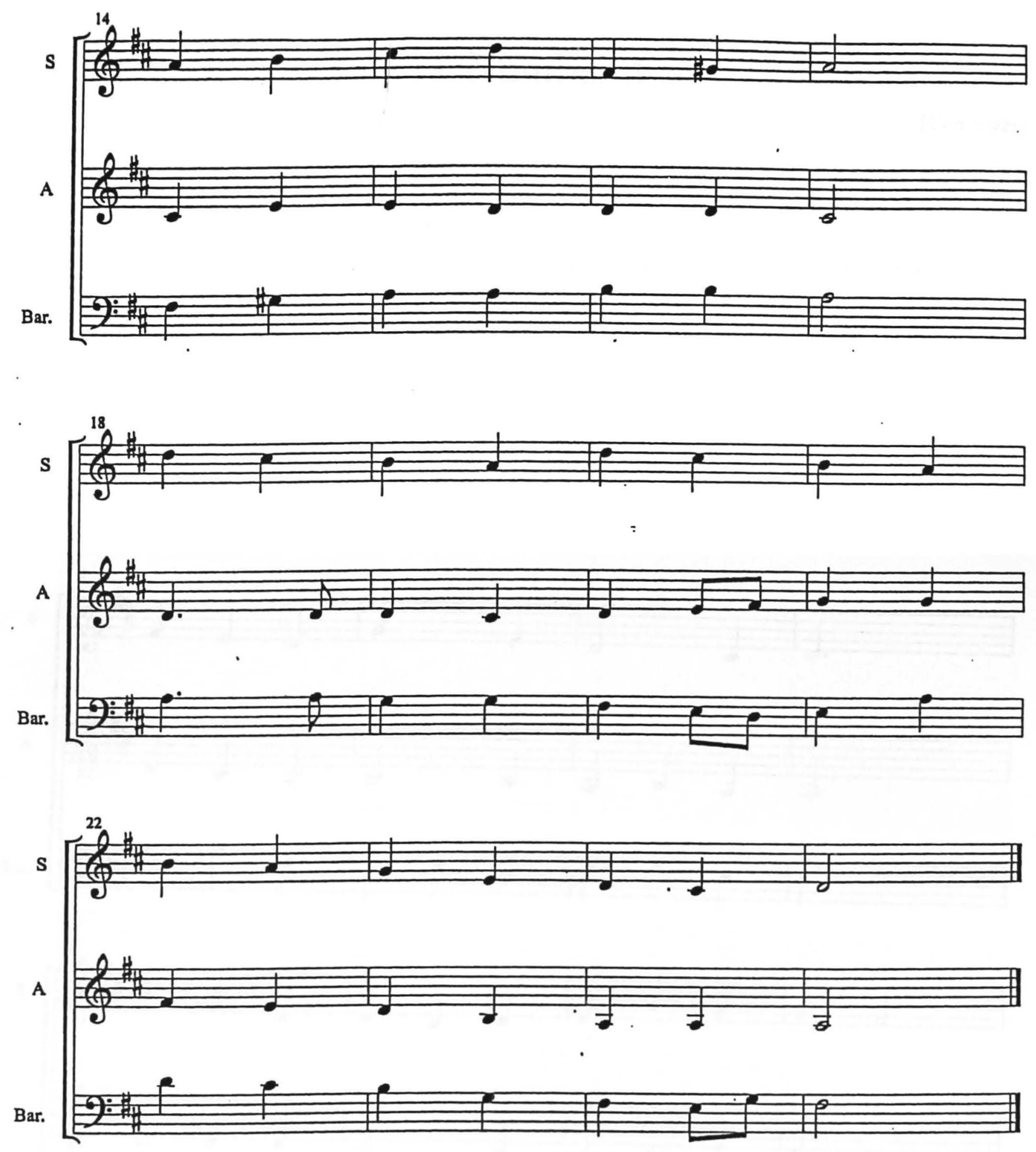
Number 4

[Composer]
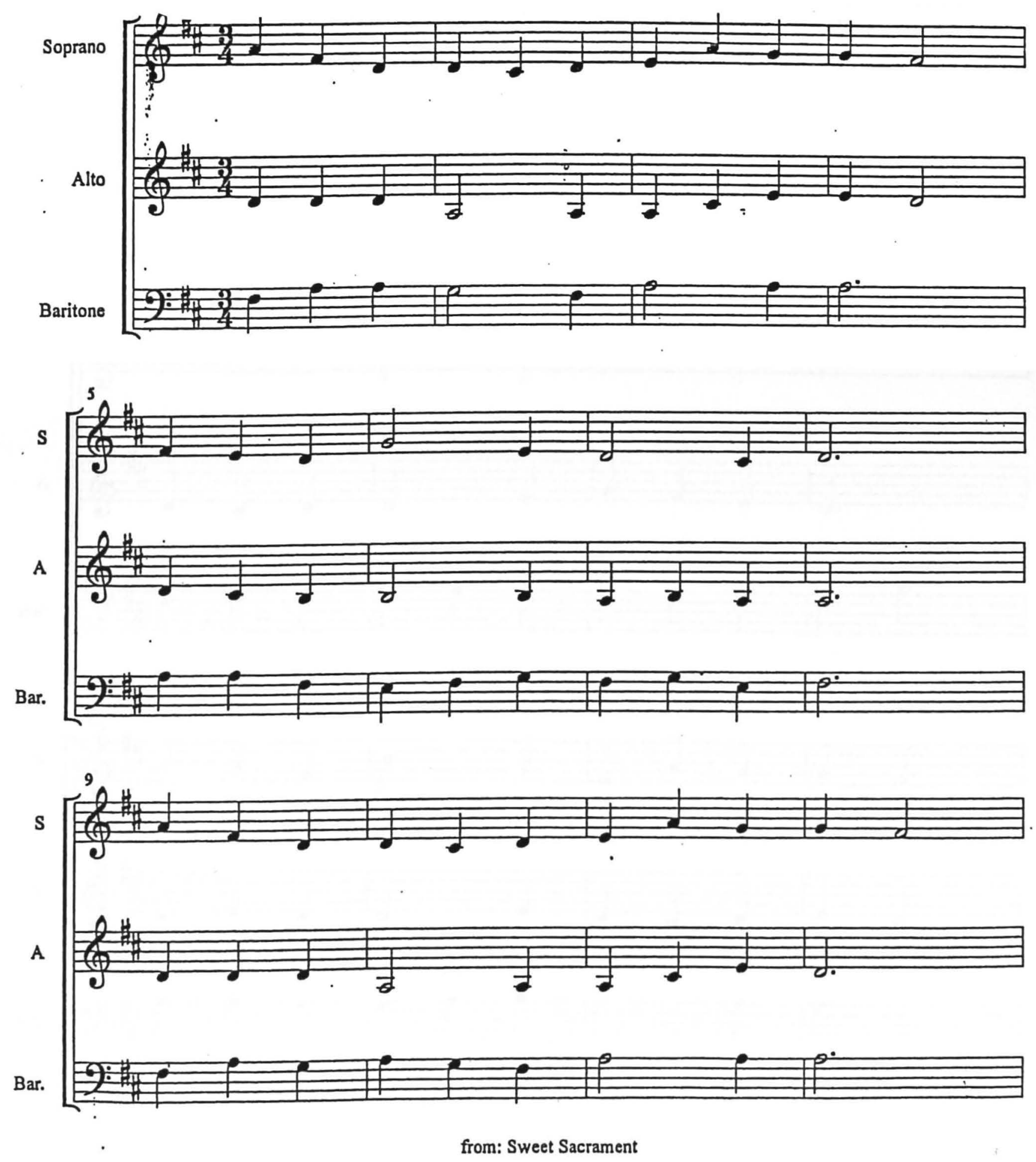

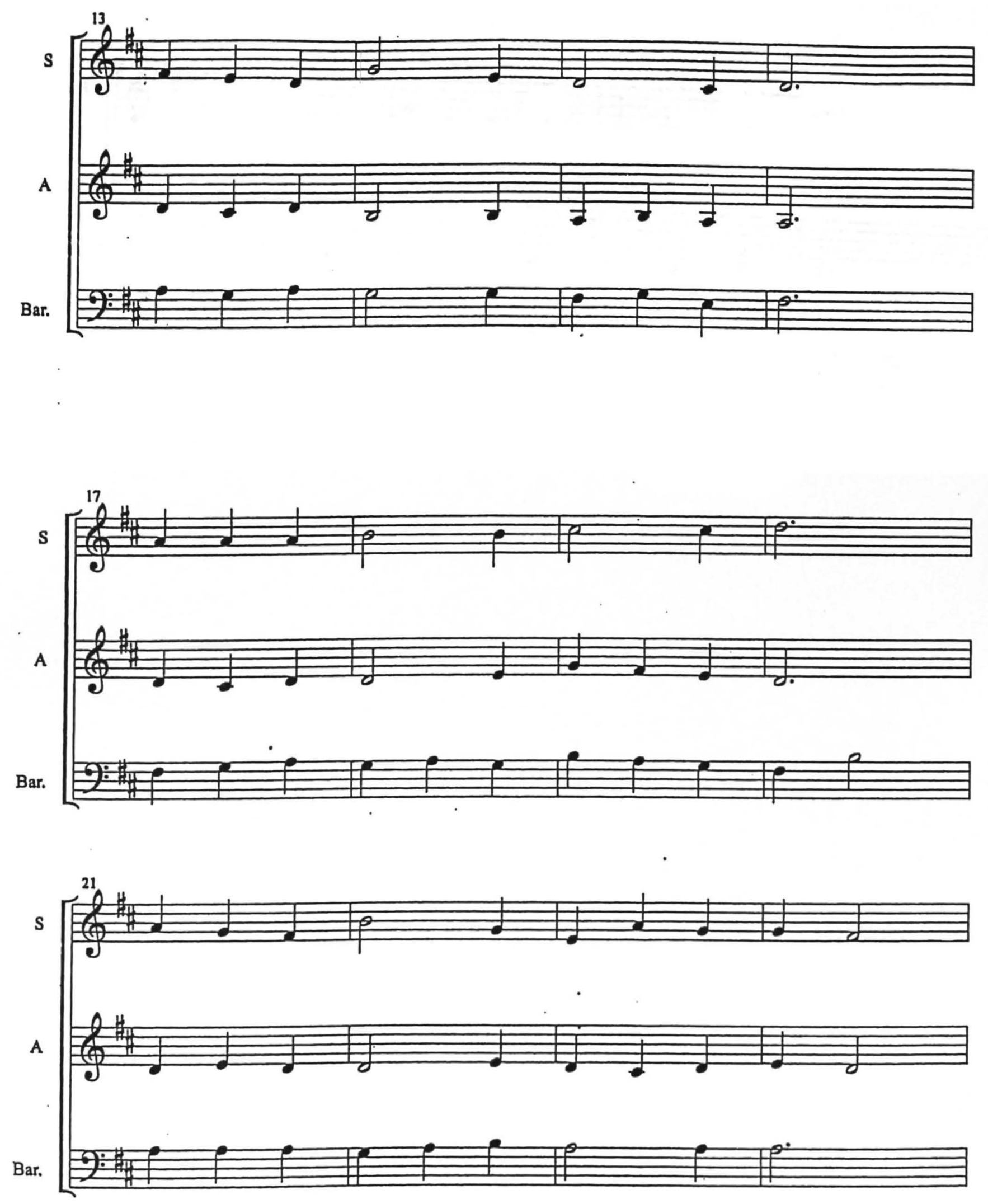


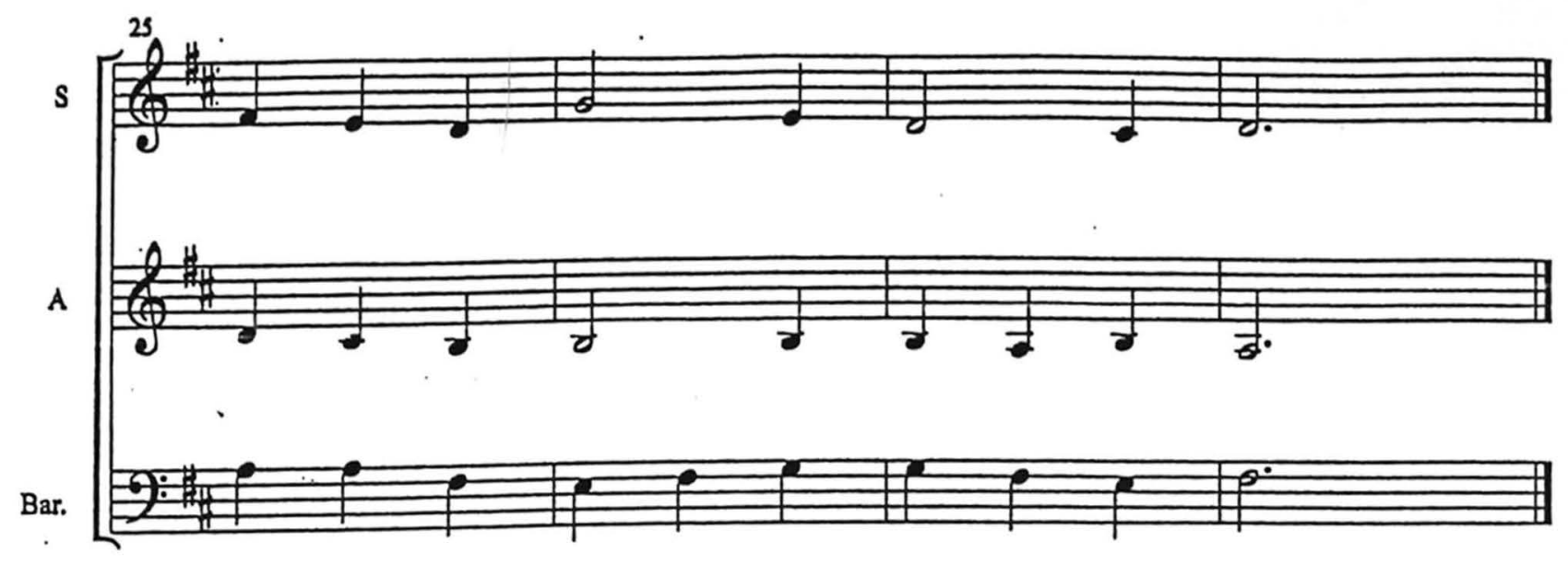

